\title{
NUMERICAL INVESTIGATION OF TIP CLEARANCE EFFECT OF ICING IN ROTOR/STATOR INTERACTION
}

\author{
R. Hayashi ${ }^{1}$, M. Yamamoto ${ }^{2}$, S. Shishido ${ }^{3}$, T. $_{\text {Murooka }}{ }^{3}$, H.Miyagawa $^{3}$ \\ ${ }^{1}$ Graduate School of Mechanical Engineering, Tokyo University of Science \\ ${ }^{2}$ Department of Mechanical Engineering, Tokyo University of Science \\ (yamamoto@rs.kagu.tus.ac.jp) \\ ${ }^{3}$ Aero-Engine and Space Operations, IHI
}

\begin{abstract}
.
Ice accretion is a phenomenon where super-cooled water droplets impinge and accrete on a body. It occurs frequently on airplanes, windmills and conductor cables. In particular, when ice layer is formed on an aircraft wing, it affects on the aerodynamic performance by increasing drag and reducing lift, and it may cause a serious accident. On a jet engine, ice accretion disturbs the inlet flow, and separated ice pieces can damage to the compressor and the casing, which leads to the severe performance degradation. There have been several accidents due to ice accretion. Therefore, the estimation of ice accretion is necessary to avoid accidents. In this study, the authors simulate icing phenomena in rotor-stator cascade considering rotor tip clearance. The numerical results indicate that the leakage vortex generated by the tip clearance changes the flow field and droplet motions, and consequently the changes makes accreted ice on the stator vane surface decrease.
\end{abstract}

Keywords: Ice Accretion, Rotor-Stator Interaction, Tip Clearance, Leakage Vortex.

\section{INTRODUCTION}

Ice accretion is a phenomenon where super-cooled water droplets impinge and accrete on a body. It has two types of ice shape. One is called 'rime ice' which is generated at very low temperature (less than $-10{ }^{\circ} \mathrm{C}$ ). On rime ice condition, droplets in the air freeze at the impingement point instantly. The other is called 'graze ice' which is generated at 0 to $-10{ }^{\circ} \mathrm{C}$. On graze ice condition, droplets gradually freeze with running along a body (so-called runback).

When ice layer is formed on an aircraft wing, it affects on the performance by increasing drag and reducing lift, and it may cause a serious accident. On a jet engine, ice accretion disturbs the inlet flow, and separated ice pieces can damage to the compressor and the casing, which leads to the severe performance degradation. There have been several instances of accidents due to ice accretion. One of most notable accidents is Air Florida Flight 90, a Boeing 
737 that crashed just after takeoff in a blizzard on January 13th, 1982. This caused 78 deaths. Another instance of a crash in flight due to ice accretion occurred on October 31st, 1994. This was American Eagle Flight 4184. This ATR-72-212, a twin turboprop airliner, was in a holding pattern around Chicago O'Hare International Airport because of weather delays. While holding, it endured freezing rain, a condition where super-cooled water droplets impacted on the wings, causing a rapid ice buildup. This led to lose the control. The most recent accident is Continental Flight 3407, a Bombardier DHC8 on February 12th, 2009. It crashed because of using an auto pilot system under icing condition, causing 50 deaths.

These cases mentioned above are only a few of the many aircraft crashes that have resulted from ice accretion. Obviously, it is essential that the mechanisms of ice accretion are understood. The estimation of ice accretion is necessary to avoid accidents and useful to reduce the cost and the design time in the design phase of aircrafts and jet engines. However, experimental investigations are very difficult, because it is not easy to set ice accretion conditions repeatedly in a wind tunnel. Therefore, it is expected computational fluid dynamics (CFD) will be a useful way to predict ice accretion phenomenon.

Icing phenomena in a jet engine tends to occur on fan blade, FEGV (fan exit guide vane), nose cone, splitter and low pressure compressor. In the previous studies, each component was individually investigated. The interaction among these components was neglected. Therefore, Kawakami et al. [1] simulated icing phenomena in a fan rotor/stator interaction field and clarified the effect of ice accretion. In particular, droplet motions, ice shape and aerodynamic performance change were numerically investigated. The results showed that thick ice forms on the hub of the rotor blade, the ice layer on the rotor blade is thicker than that on the stator vane, the ice accretion on a fan blade has considerable effect on the flow field and icing phenomena on the stator vane and so on. However, in their study the effect of tip clearance was not taken into account.

In the present study, considering the above backgrounds, ice accretions in a rotorstator cascade with and without the tip clearance are simulated. In order to clarify the effect of tip clearance on icing phenomena, the numerical results are visualized and investigated.

\section{NUMERICAL PROCEDURE}

The three-dimensional ice accretion codes used in this study are composed of iterative computations for fluid motion, droplet trajectory, thermodynamics and grid modification. Below each computational detail is explained.

\subsection{Flow field}

The flow field is assumed to be three-dimensional, compressible and turbulent. The governing equations are Favre-averaged continuity, Navier-Stokes and energy equations. Coriolis force and centrifugal force are added as body forces. The Kato-Launder $k-\varepsilon$ turbulence model (Kato and Launder, [2]) is applied to estimate turbulence. The governing equations are discretized using second-order upwind TVD scheme (Yee and Harten, [3]) for the 
inviscid terms, second-order central difference scheme for the viscous ones, and LU-ADI scheme (Fujii and Obayashi, [4]) for the time integration.

\subsection{Droplet trajectory}

Droplet trajectory calculation based on a Lagrangian approach is performed to obtain the droplet collection efficiency on the blade. The calculation uses the following assumptions:

(1) The droplet is spherical.

(2) The droplet is sufficiently small, and thus it does not break up.

(3) The forces acting on the droplet are the drag, centrifugal force and Coriolis force.

(4) The droplets do not interact with each other.

(5) The droplets do not affect on the flow field (one-way coupling).

(6) The initial droplet velocity is equal to the gas velocity at the release point.

The equation of droplet motion is

$$
\frac{d \vec{U}_{w}}{d t}=\frac{3}{4} C_{D} \frac{\rho_{f}}{\rho_{w}} \frac{1}{d_{w}} \vec{U}_{r}\left|\vec{U}_{r}\right|-\left\{2 \vec{\Omega} \times \vec{U}_{w}-\vec{\Omega} \times\left(\vec{\Omega} \times \vec{r}_{w}\right)\right\}
$$

where $t$ is the time, $U_{w}$ is the droplet velocity, $U_{r}$ is the relative velocity between the gas and the droplet, $d_{w}$ is the droplet diameter, and $\rho_{f}$ and $\rho_{w}$ are the gas and the droplet density. The second term on the RHS represents the centrifugal force and Coriolis force, where $\Omega$ is the rotational speed, and $r_{w}$ is the radial position of the droplet. The drag coefficient $C_{D}$ is expressed as:

$$
C_{D}=\frac{24}{\operatorname{Re}_{w}}\left(1+0.15 \operatorname{Re}_{w}^{0.687}\right)
$$

where $\mathrm{Re}_{w}$ is the Reynolds number of the droplet based on the diameter and the relative velocity between the gas and the droplet.

\subsection{Thermodynamics}

The thermodynamic calculation is performed by use of the extended Messinger model [5]. This model is based on a standard method of phase change, i.e., the Stefan problem. The phase change problem is governed by four equations. They can be expressed as

$$
\begin{gathered}
\frac{\partial T_{i}}{\partial t}=\frac{k_{i}}{\rho_{i} C_{p i}} \frac{\partial^{2} T_{i}}{\partial y^{2}} \\
\frac{\partial T_{w}}{\partial t}=\frac{k_{w}}{\rho_{w} C_{p w}} \frac{\partial^{2} T_{w}}{\partial y^{2}}
\end{gathered}
$$




$$
\begin{gathered}
\rho_{i} \frac{\partial B_{i}}{\partial t}+\rho_{w} \frac{\partial B_{w}}{\partial t}=m_{i m}+m_{i n}-m_{e, s} \\
\rho_{i} L_{F} \frac{\partial B_{i}}{\partial t}=k_{i} \frac{\partial T_{i}}{\partial y}-k_{w} \frac{\partial T_{w}}{\partial y}
\end{gathered}
$$

where Eqs. (3) and (4) are the energy equations in the ice and water layers respectively, Eq. (5) is the mass conservation equation and Eq. (6) is the phase change condition at the ice/water interface. In these equations, $T_{i}$ and $T_{w}$ are the temperatures of ice and water; $B_{i}$ and $B_{w}$ are the thicknesses of ice and water layers; $k_{i}$ and $k_{w}$ are the thermal conductivities of ice and water; $C_{p i}$ and $C_{p w}$ are the specific heats of ice and water; $m_{i m}, m_{i n}$ and $m_{e, s}$ are impinging, runback and evaporating (or sublimating) water mass flow rates for a control volume, respectively; $\rho_{i}$ and $\rho_{w}$ are the density of ice and water; $L_{F}$ denotes the latent heat of solidification of water. Ice density is assumed to have two different values for rime ice $\rho_{r}$ and glaze ice $\rho_{g}$ (see Table [1]). The coordinate $y$ is normal to the surface. In order to determine the ice and water thicknesses together with the temperature distribution at each layer, boundary and initial conditions must be specified. These are based on the following assumptions:

(1) Ice is in perfect contact with the blade surface, whose temperature is equal to the air temperature $T_{a}$ :

$$
T_{i}(0, t)=T_{s}=T_{a}
$$

(2) The temperature is continuous at the ice/water boundary and is equal to the freezing temperature $T_{f}$ :

$$
T_{i}(B, t)=T_{w}(B, t)=T_{f}
$$

(3) At the air/water (glaze ice) or air/ice (rime ice) interface, heat flux is determined by convection $\left(Q_{c}\right)$, radiation $\left(Q_{r}\right)$, latent heat release $\left(Q_{l}\right)$, cooling by incoming droplets $\left(Q_{d}\right)$, heat brought in by runback water $\left(Q_{i n}\right)$, evaporation $\left(Q_{e}\right)$ or sublimation $\left(Q_{s}\right)$, aerodynamic heating $\left(Q_{a}\right)$ and kinetic energy of incoming droplets $\left(Q_{k}\right)$ :

Table 1 Parameter of extended Messinger model

\begin{tabular}{cl|c}
\hline Specific heat of ice $C_{p i}$ & {$[\mathrm{~J} / \mathrm{kg} \mathrm{K}]$} & 2050 \\
\hline Specific heat of water $C_{p w}$ & {$[\mathrm{~J} / \mathrm{kg} \mathrm{K}]$} & 4218 \\
\hline Thermal conductivity of ice $k_{i}$ & {$[\mathrm{~W} / \mathrm{m} \mathrm{K}]$} & 2.18 \\
\hline Thermal conductivity of water $k_{w}$ & {$[\mathrm{~W} / \mathrm{m} \mathrm{K}]$} & 0.571 \\
\hline Latent heat of solidification $L_{F}$ & {$[\mathrm{~J} / \mathrm{kg}]$} & $3.344 \times 10^{5}$ \\
\hline Density of rime ice $\rho_{r}$ & {$\left[\mathrm{~kg} / \mathrm{m}^{3}\right]$} & 880.0 \\
\hline Density of glaze ice $\rho_{g}$ & {$\left[\mathrm{~kg} / \mathrm{m}^{3}\right]$} & 917.0 \\
\hline Density of water $\rho_{w}$ & {$\left[\mathrm{~kg} / \mathrm{m}^{3}\right]$} & 1000 \\
\hline
\end{tabular}




$$
\begin{aligned}
& \text { Glaze ice : }-k_{w} \frac{\partial T_{w}}{\partial t}=\left(Q_{c}+Q_{e}+Q_{d}+Q_{r}\right) \\
& -\left(Q_{a}+Q_{k}+Q_{\text {in }}\right) \text { at } y=B_{i}+B_{w} \\
& \text { Rime ice : }-k_{i} \frac{\partial T_{i}}{\partial t}=\left(Q_{c}+Q_{s}+Q_{d}+Q_{r}\right) \\
& -\left(Q_{a}+Q_{k}+Q_{i n}+Q_{l}\right) \text { at } y=B_{i}
\end{aligned}
$$

(4) Blade surface is initially clean:

$$
B_{i}=B_{w}=0, \text { at } \quad t=0
$$

\section{COMPUTATIONAL CONDITION}

\subsection{Computational domain and grids}

Icing phenomena in a jet engine tend to occur in the fan blade, FEGV (fan exit guide vane), nose cone, splitter and compressor (see Figure 1). In this work, we focus on a fan blade and a FEGV. The schematic diagram of the fan blade and the FEGV is shown in Figure 2. The jet engine has twenty-four rotor blades and sixty stator vanes. For simplicity, only one rotor blade and two stator vanes are simulated, assuming the geometrical periodicity. The computational grid based on an overset grid method and a multi block method is exhibited in Figure 3; (a) is the main grid for the passage, (b) is the sub grid around the blade, and (c) is the sub grid at the tip clearance to clarify the flow field at this region. Each number of the grid points is listed in Table 2. The total number of the grid points is about three million. Note that for the rotor blade the relative coordinate system is used, and for the others the absolute coordinate system is employed.

\subsection{Operating condition}

The computational conditions in this work are summarized in Table 3. The total pres-

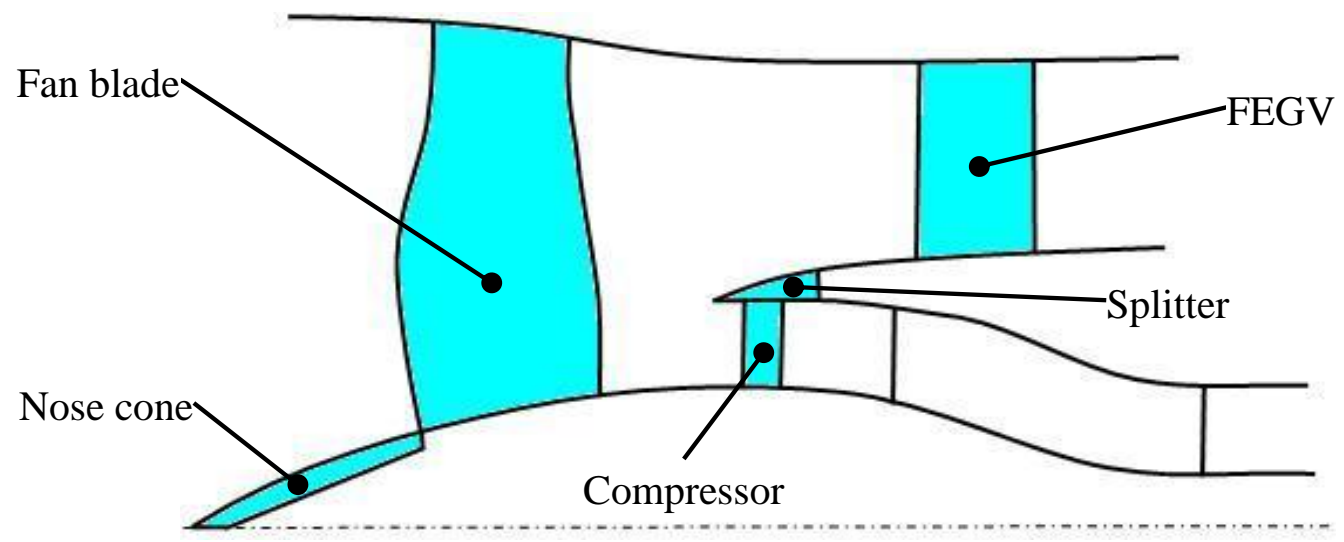

Figure 1 Icing area of jet engine (shaded) 


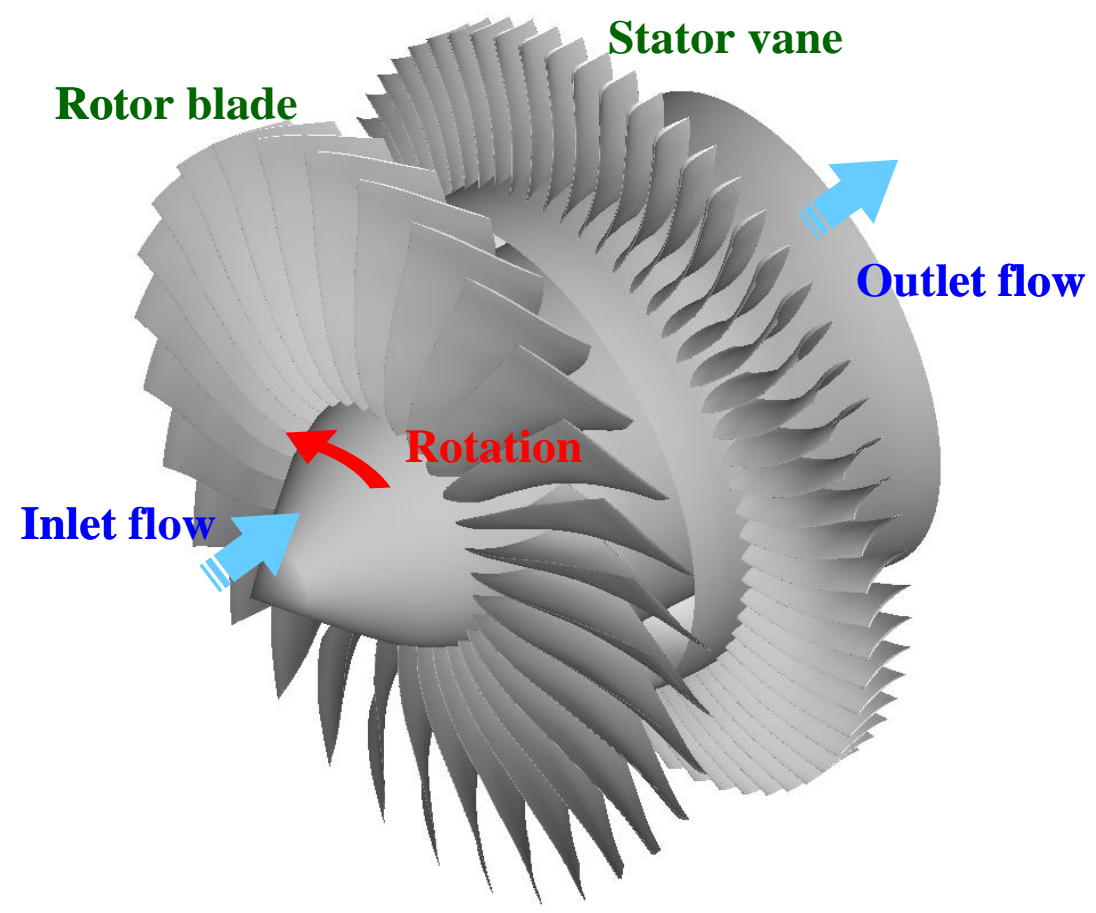

Figure 2 Schematic diagram of rotor fan and FEGV

Table 2 Computational grid point

\begin{tabular}{c|c}
\hline Rotor main grid & $161 \times 41 \times 71$ \\
\hline Rotor sub grid & $201 \times 31 \times 91$ \\
\hline Stator main grid & $151 \times 60 \times 71$ \\
\hline Stator sub grid & $201 \times 31 \times 91 \times 2$ \\
\hline Core main grid & $22 \times 41 \times 31$ \\
\hline Tip clearnce sub grid & $71 \times 31 \times 91$ \\
\hline Total grid point & $3,041,247$ \\
\hline
\end{tabular}

Table 3 Incoming flow and icing conditions

\begin{tabular}{|c|c|c|}
\hline Rotating tip speed & {$[\mathrm{m} / \mathrm{s}]$} & 300 \\
\hline Inlet mach number & & 0.44 \\
\hline Inlet total pressure & [MPa] & 0.1013 \\
\hline Inlet total temperature & {$[\mathrm{K}]$} & 253.15 \\
\hline LWC (Liquid water content) & {$\left[\mathrm{g} / \mathrm{m}^{3}\right]$} & 1.0 \\
\hline MVD (Median volume diameter) & {$[\mu \mathrm{m}]$} & 20,50 \\
\hline Exposure time & {$[\mathrm{s}]$} & 3.0 \\
\hline
\end{tabular}

sure, the total temperature and the Mach number at the inlet are averaged from the tip to the hub. The LWC means the liquid water content, and the MVD is the median volume diameter of droplets. The droplet trajectory simulations are conducted for 10,000,000 droplets spatially distributed at the computational upstream boundary. The initial droplet velocity is equal to the local gas velocity. 


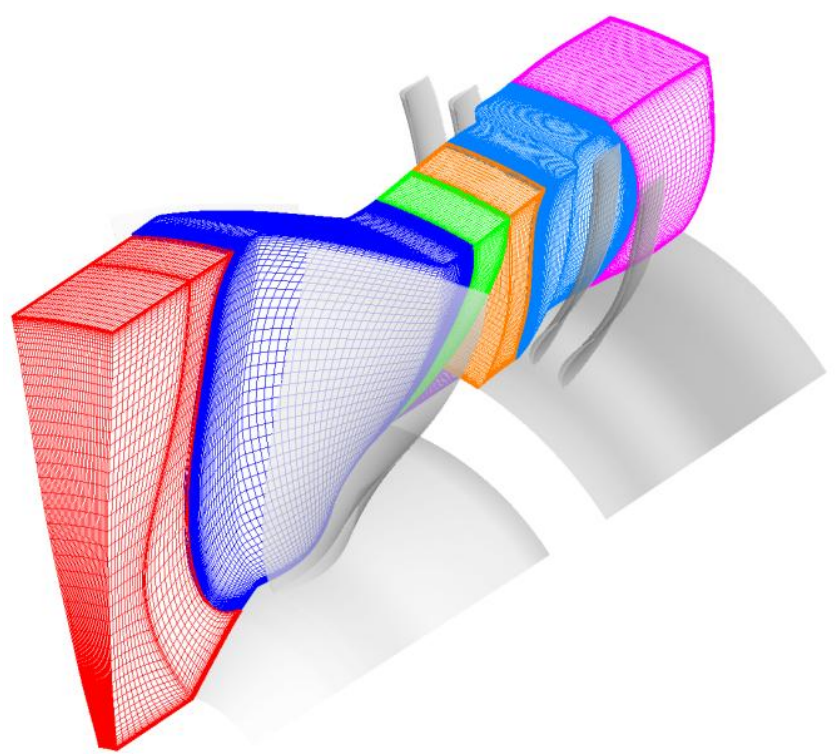

(a) Main grid for passage

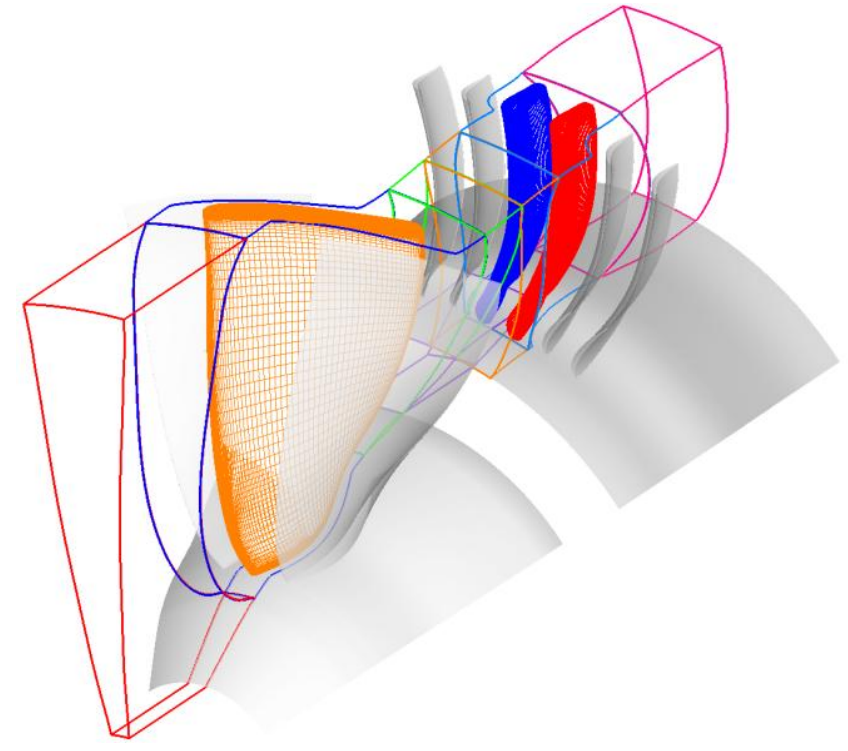

(b) Sub grid around blade

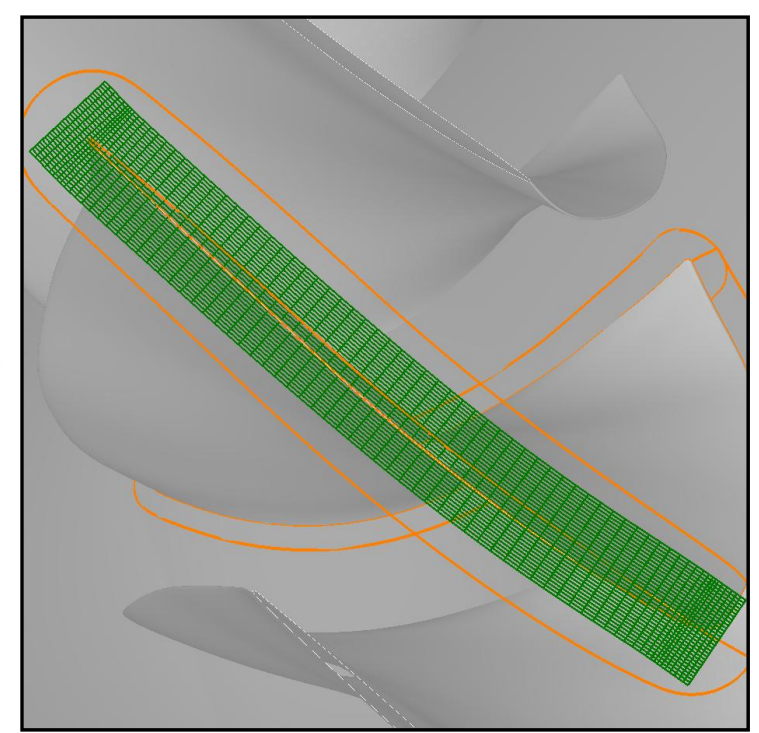

(c) Sub grid at tip clearance

Figure 3 Computatinal grid

\subsection{Boundary condition}

Total pressure, total temperature and flow angle are imposed, and Mach number is extrapolated at the upstream inflow boundary. Adiabatic, no slip and wall function boundary conditions are prescribed on the stationary and rotating surfaces. The exit static pressure is specified. The inflow kinetic energy is imposed by the $0.1 \%$ turbulence of the free stream. 


\section{RESULT AND DISCUSSION}

\subsection{Flow field}

The relative Mach number distribution around the rotor blade is shown in Figure 4. At the hub side, the Mach number is about 0.3 due to the inner casing wall, and a small separation can be seen near the trailing edge. At the midspan, the high Mach number region is formed near the leading edge, where the Mach number is over the local sound speed. We cannot observe flow separation at the midspan. The Mach number at the wake of the rotor blade is small. The Mach number of the incoming at the $95 \%$ span is very large, which is about 1.2. The high Mach number flow impinges on the rotor blade, and decreases the Mach number

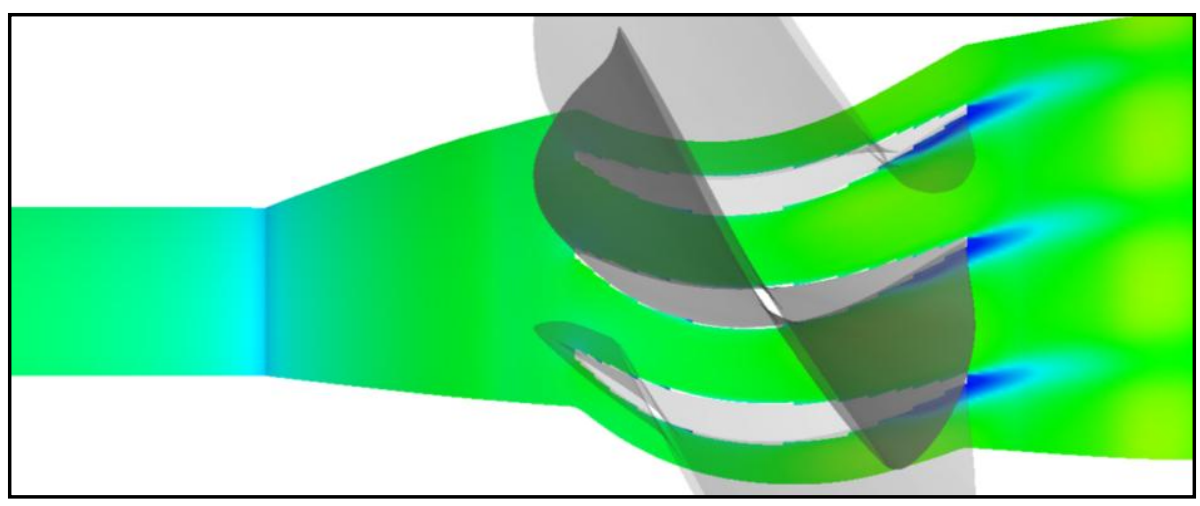

(a) $5 \% \operatorname{span}$

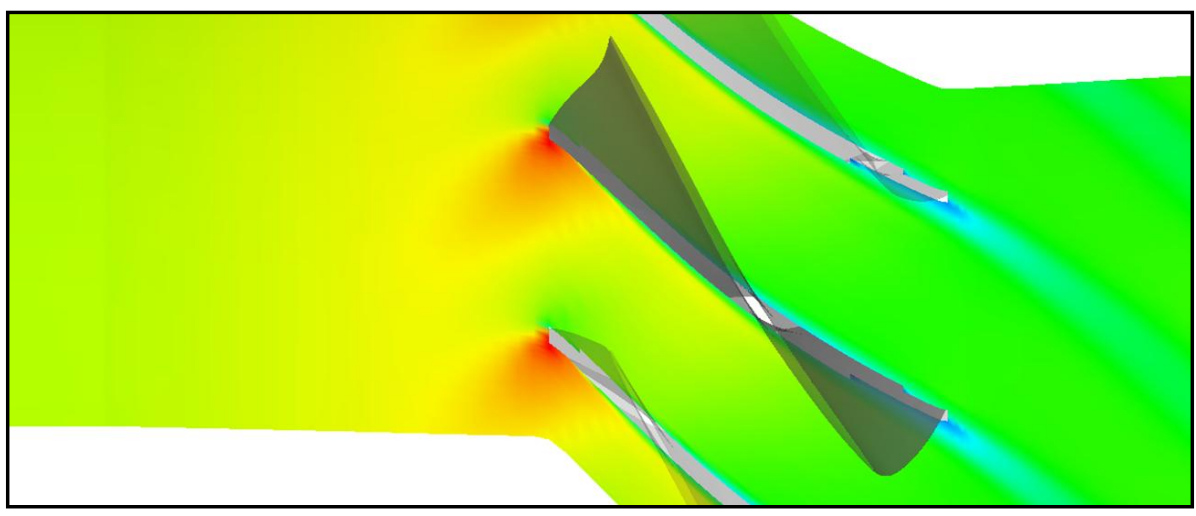

(b) Midspan
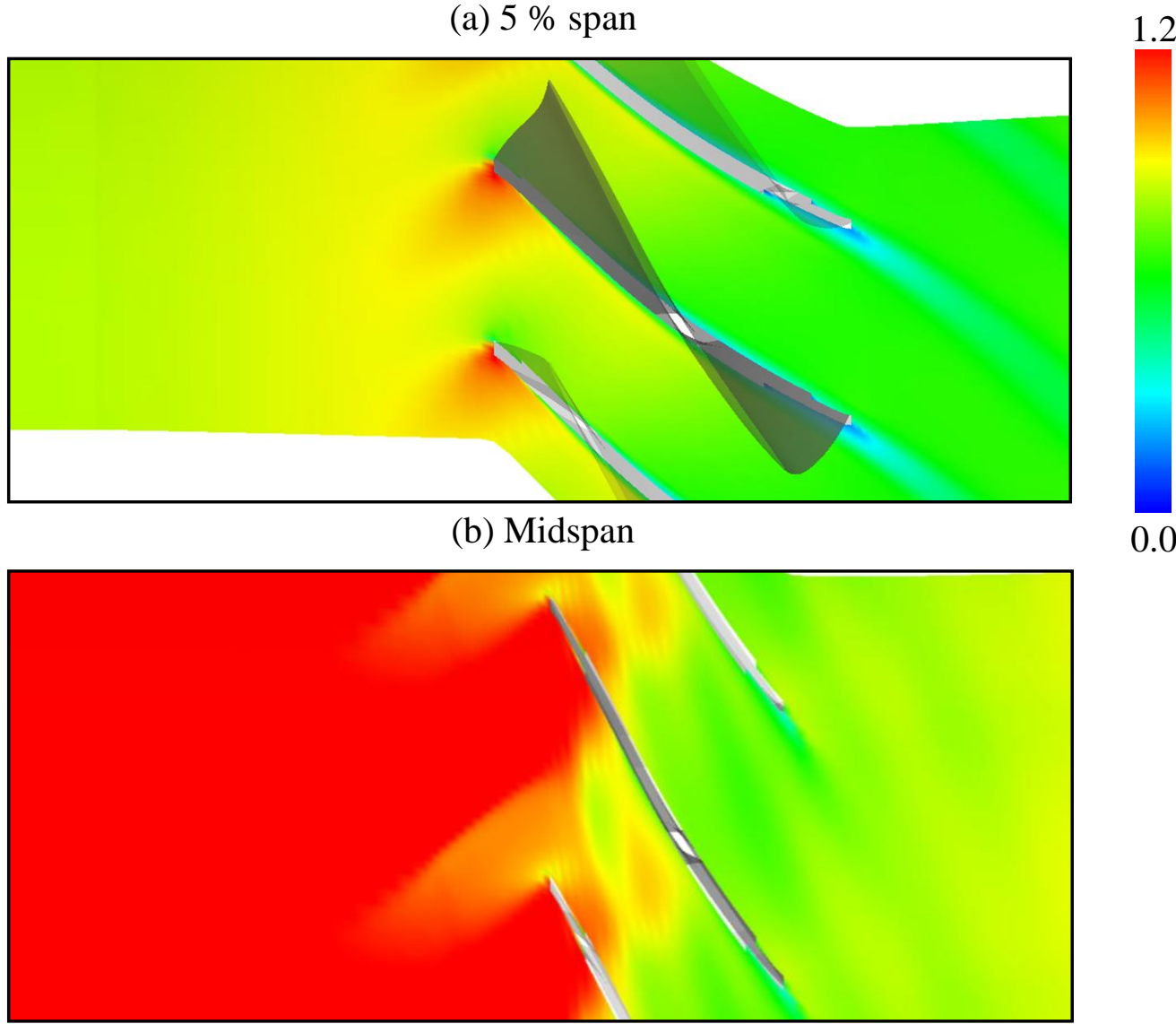

0.0

(c) $95 \%$ span

Figure 4 Relative Mach number distribution at rotor blade 
throuth the shock wave. Additionally, the Mach number distribution at the $95 \%$ span is remarkably non-uniform in comparison with other span sections, because the leakage vortex disturbs the flow neat the tip clearance.

Figure 5 shows the static temperature distribution at the rotor midspan; (a) is at the phase angle of 0 deg., (b) is at $120 \mathrm{deg}$. and (c) is at $240 \mathrm{deg}$., respectively. At the leading edge of the rotor blade, the static temperature is considerably low (about $220 \mathrm{~K}$ ) due to the high Mach number region. Therefore, there would be high probability that this region is subject to the formation of ice in comparison with the other regions. Also, we can see that the wake of the rotor blade flows into the stator vane passages, and the temperature change of the stator vane is periodic. The wake of the rotor blade which has high temperature impinges on the leading edge of the stator vane, and so the temperature around the leading edge of the stator vane becomes high. The static temperature is locally about $280 \mathrm{~K}$ at the exit of the stator cascade. Therefore, the flow field around the stator vane has a significant effect of the rotor blade. In particular, the wake of the rotor blade strongly affects on the stator vane at the suction side. On the other hand, the flow field around the rotor blade has little effect of the stator

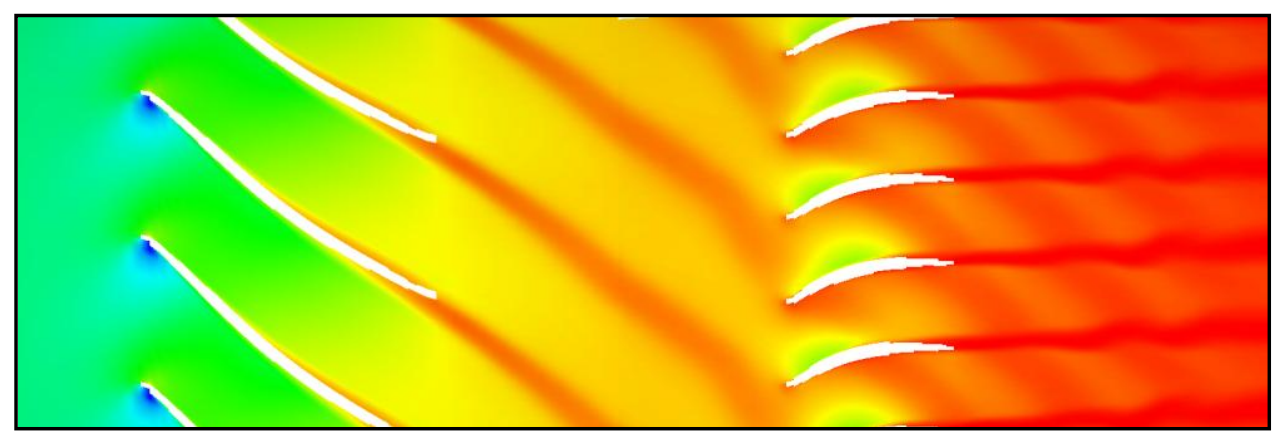

(a) 0 deg.

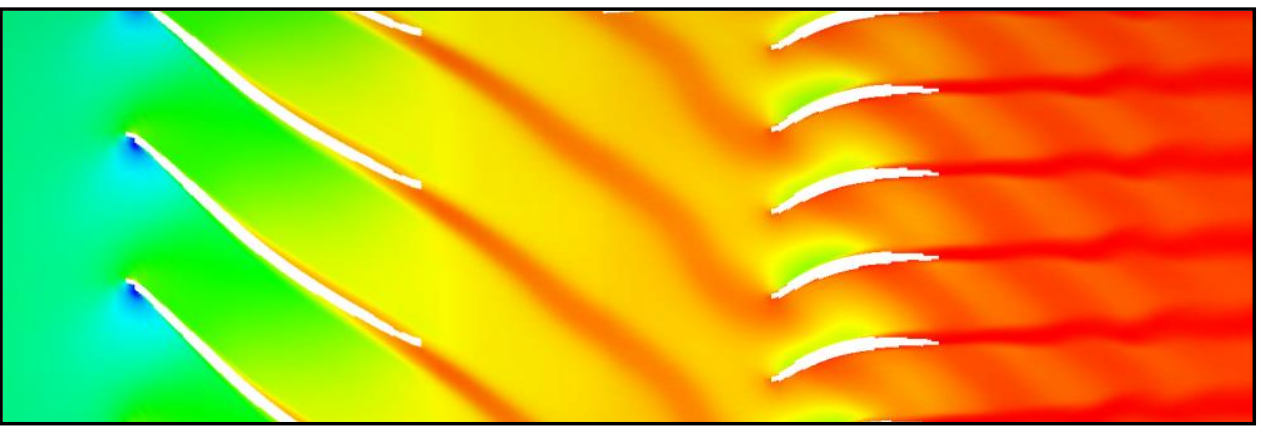

(b) $120 \mathrm{deg}$.
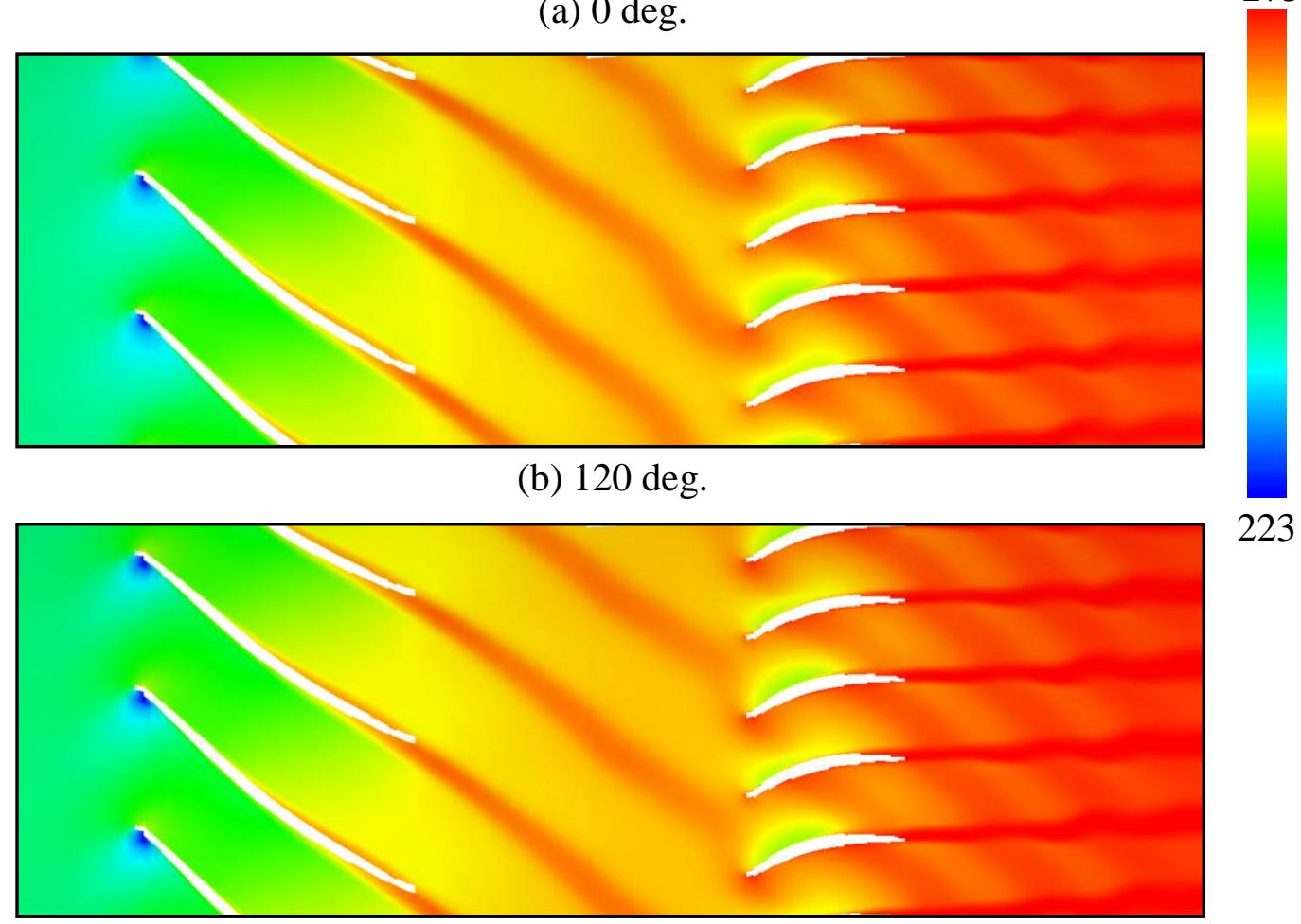

(c) $240 \mathrm{deg}$.

Figure 5 Static temperature distribution at rotor midspan 
vane.

The leakage vortex structure visualized by LIC (Line Integral Convolution) method [6] near the tip is shown in Figure 6. The red zone represents the rotor blade and the gray one represents vortex structure in this figure. In this study, the leakage vortex is clearly formed near the tip when the tip clearance is considered. The leakage vortex is further from the blade surface at the suction side as the flow goes along the rotor blade. This leakage vortex would have an influence on the wake of the rotor blade and the flow field at the stator vane, and thus it would change icing phenomena at the stator vane.

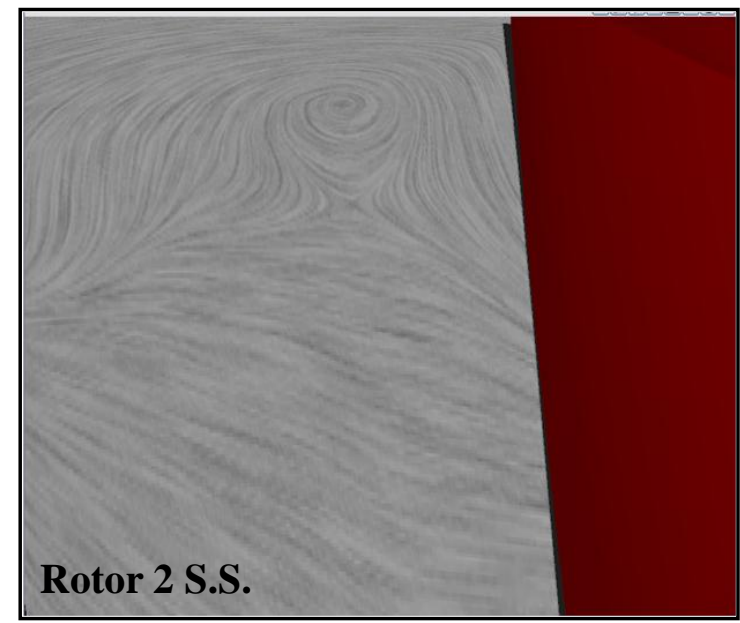

(a) $30 \%$ chord

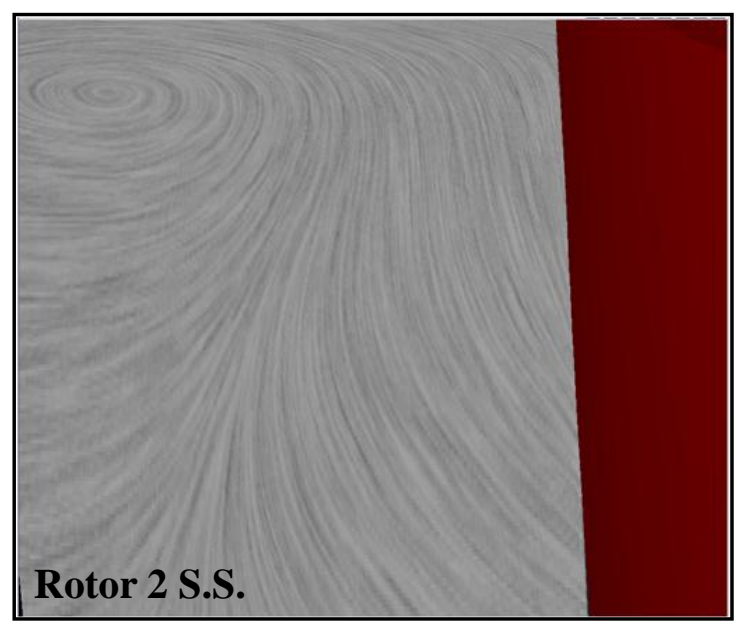

(b) $50 \%$ chord

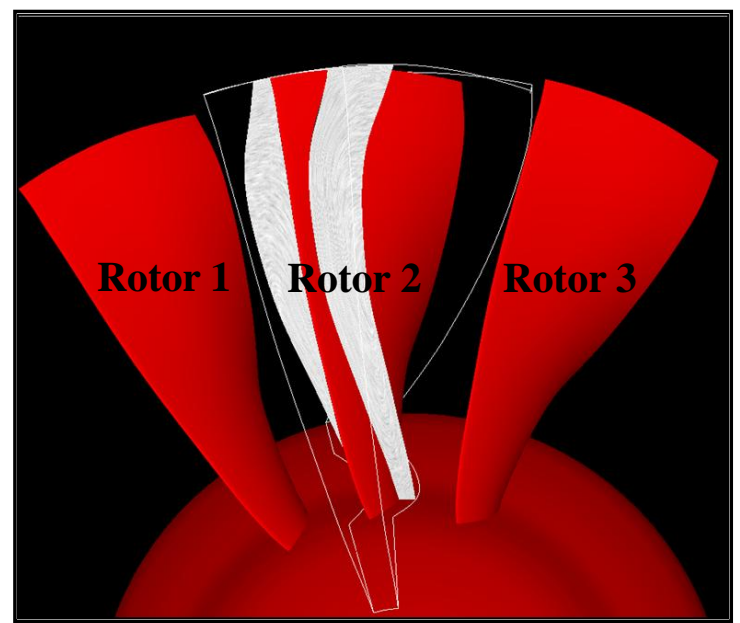

Cross section (30\% chord)

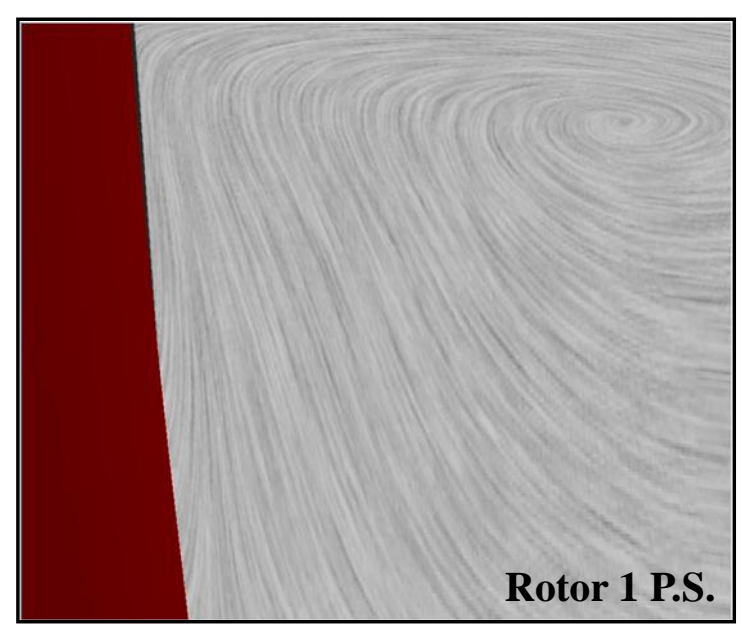

(c) $70 \%$ chord

Figure 6 Vortex structure near tip clearance

\subsection{Droplet trajectories}

The droplet trajectories are indicated in Figures 7 and 8. One is the case with the tip clearance and the other is the case without the tip clearance. In the both cases $20 \mu \mathrm{m}$ droplet diameter is assumed. In this section, we will compare the droplet trajectories between the cases with and without the tip clearance. In the case with the tip clearance, the droplet near the rotor blade tip is slow down, and this slow droplet impinges on the stator casing without 
reaching at the stator vane. The reason why the leakage vortex forms the low-speed region near the tip of the rotor blade and this slow droplet impinge on the stator casing so that the centrifugal force dominantly acts on. On the other hand, the velocity of the droplet is kept after passing near the tip of the rotor blade in the case without the tip clearance, and the droplet reaches at the stator vane. Clearly, this difference influences on the collection efficiency on the stator vane.

In the case of $50 \mu \mathrm{m}$ droplet diameter, droplet trajectories are different from those of 20

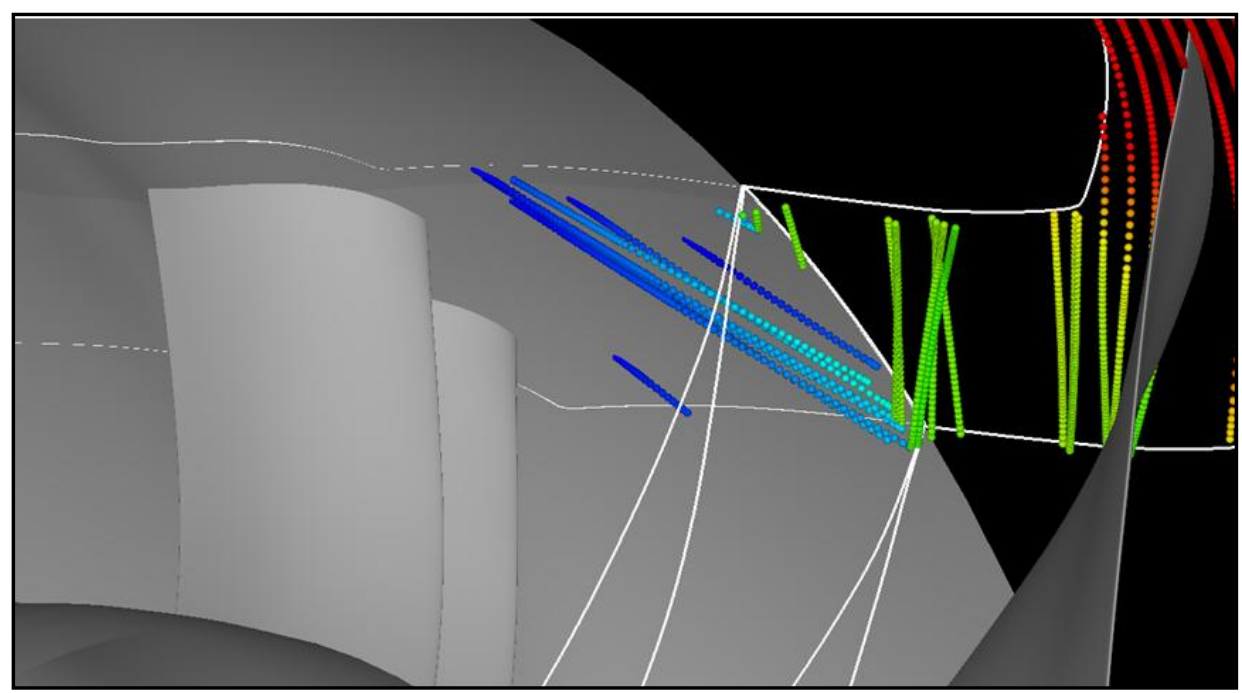

(a) Over view

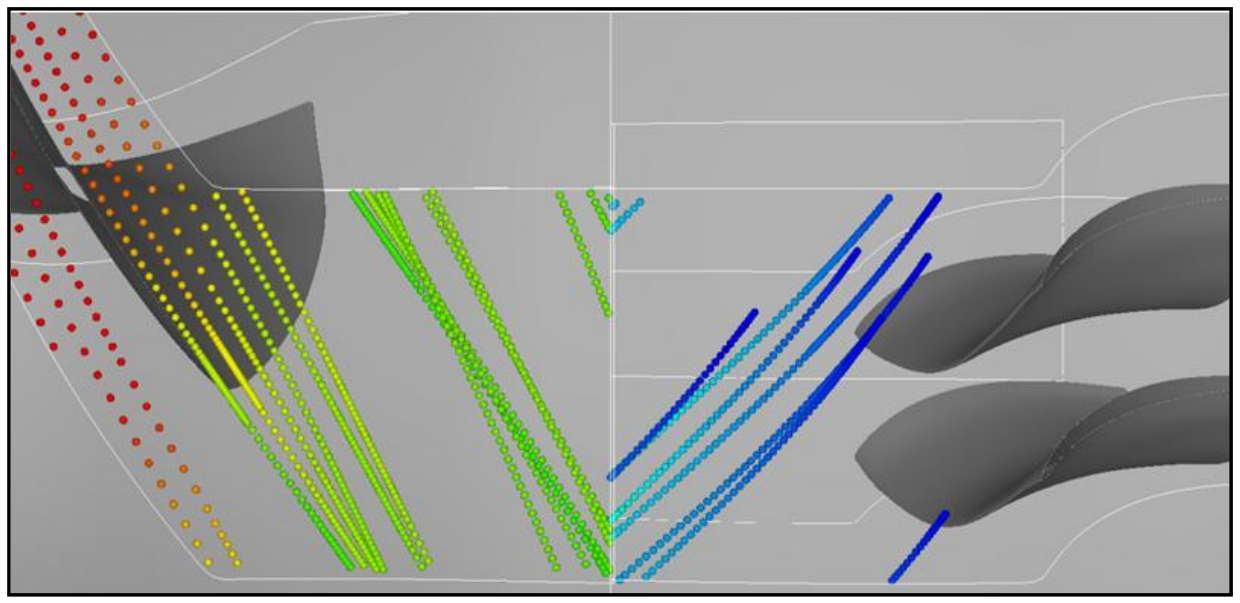

(b) Top view
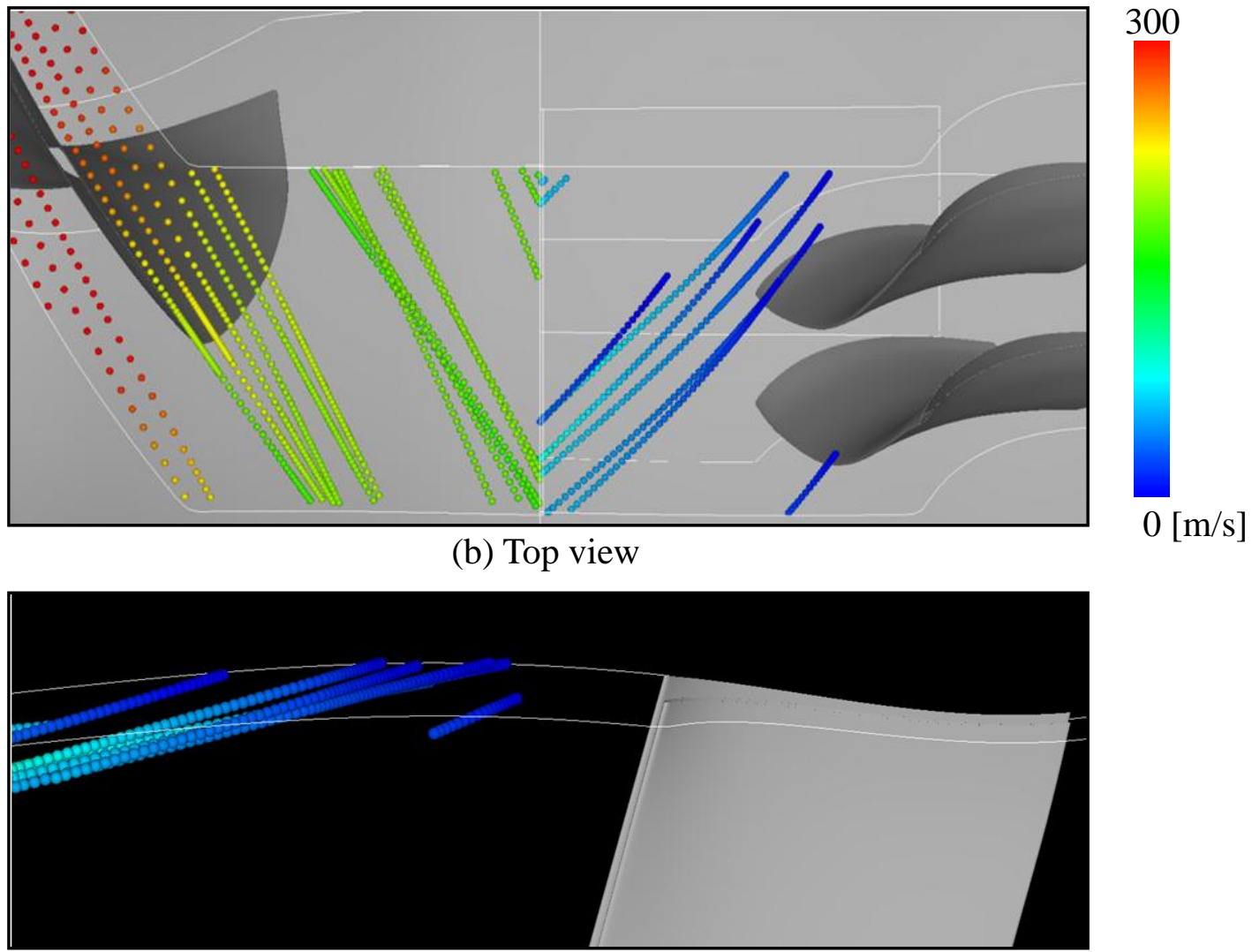

(c) Side view

Figure 7 Droplet trajectories with tip clearance. (MVD $20 \mu \mathrm{m})$ 
$\mu \mathrm{m}$ droplet diameter due to the increase of the inertial force. The impingement areas at the rotor blade are compared in Figure 9. This figure is viewed from the suction side, and the red area represents the impingement area. In the case of $20 \mu \mathrm{m}$ droplet diameter, the impingement area is limited from the hub side to the midspan, which means the droplet hardly impinges on the tip side. However, in the case of $50 \mu \mathrm{m}$ droplet diameter, the impingement area spreads from the hub side to the tip side. Therefore, the tip clearance has more or less effect on the ice accretion at the rotor blade in the case of $50 \mu \mathrm{m}$ droplet diameter unlike the case of $20 \mu \mathrm{m}$ droplet diameter.

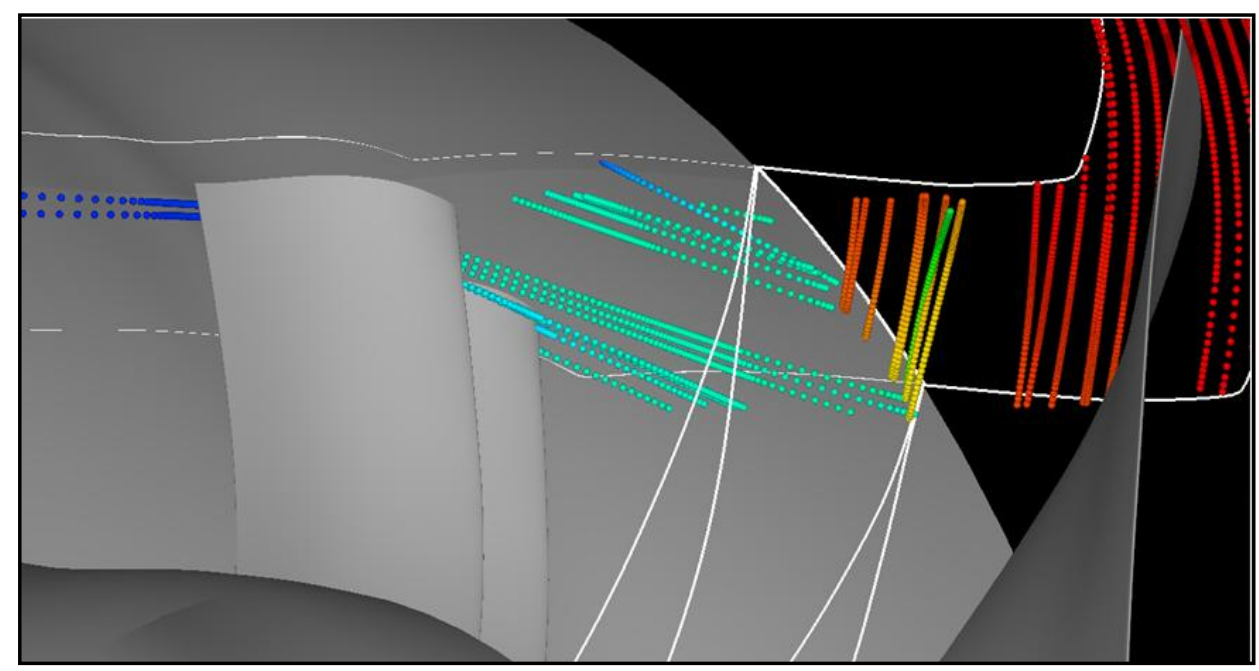

(a) Over view
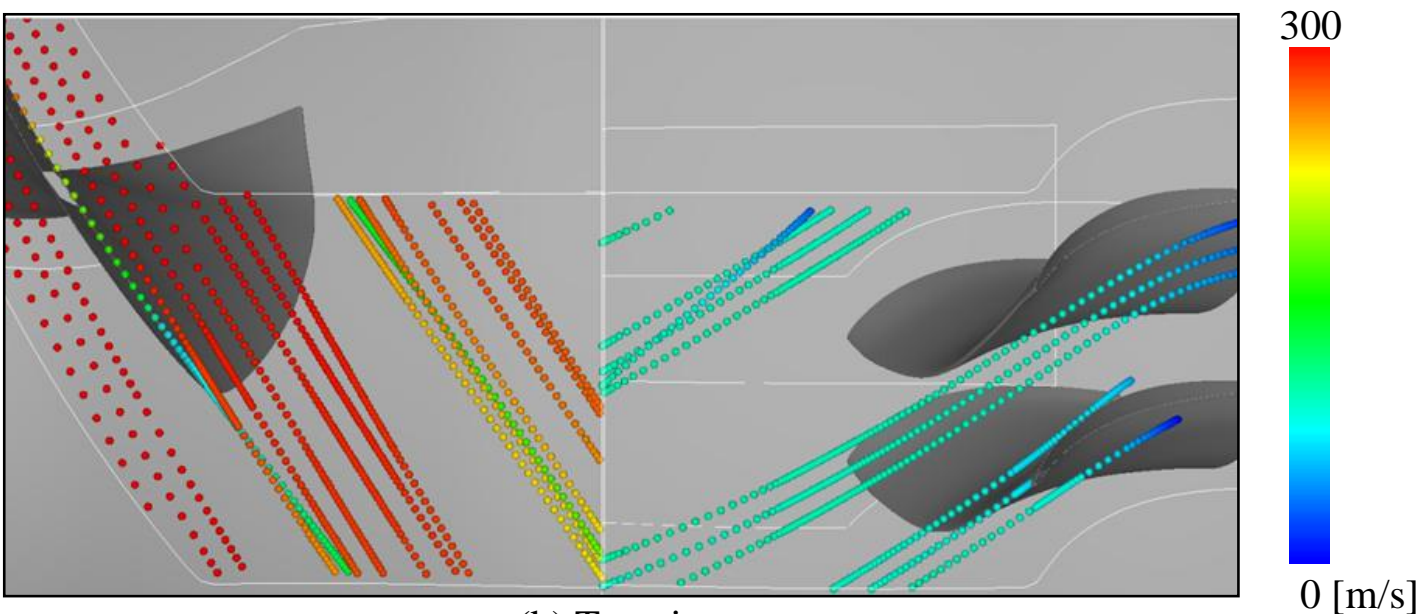

(b) Top view

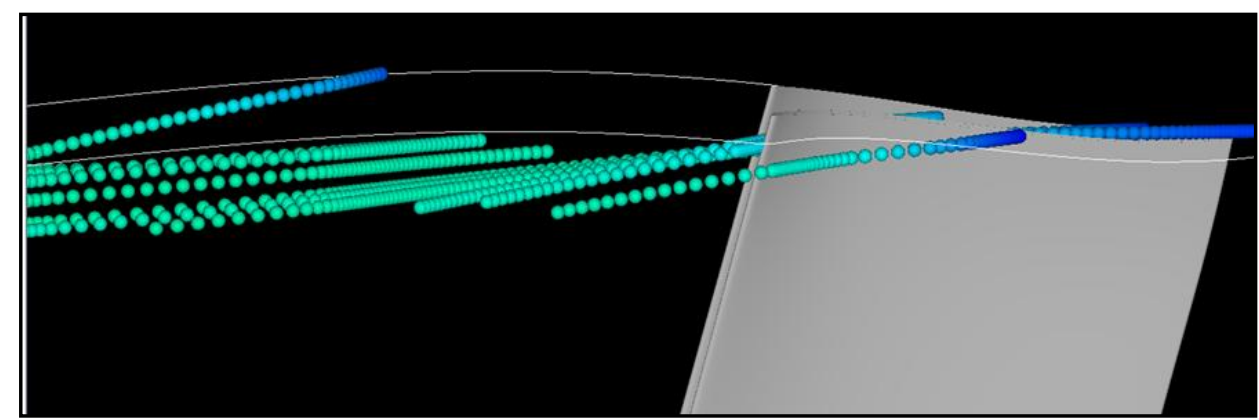

(c) Side view

Figure 8 Droplet trajectories without T.C. (MVD $20 \mu \mathrm{m}$ ) 


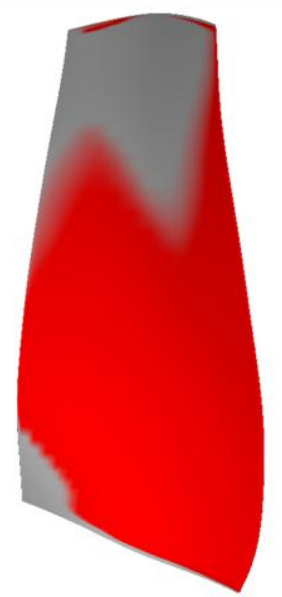

(a) MVD $20 \mu \mathrm{m}$

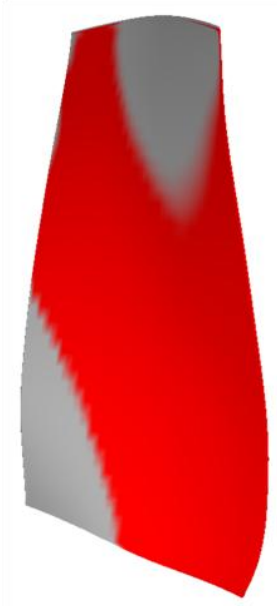

(b) MVD $50 \mu \mathrm{m}$

Figure 9 Difference of impingement area by droplet diameter at rotor suction side

\subsection{Ice accretion}

Finaly, we would like to show the effect of the tip clearance on icing phenomena of the stator vane. Effects of the tip clearance in the case of $20 \mu \mathrm{m}$ droplet diameter are exhibited in Figure 10; (a) is the ice thickness, (b) is the collection efficiency, and (c) is the blade surface temperature. These figures illustrate the stator vane viewed from the inlet in the case of $20 \mu \mathrm{m}$ droplet diameter. In Figure 10 (a), the ice thickness near the tip in the case with the tip clearance is less than that in the case without the tip clearance. In the case with the tip clearance, the collection efficiency decreases near the tip in Figure 10 (b) and the blade surface temperature increases near the tip in Figure 10 (c). Both phenomena lead to the reduction of the ice thickness near the tip. The increase of the blade surface is only about $5 \mathrm{~K}$, but it has a large

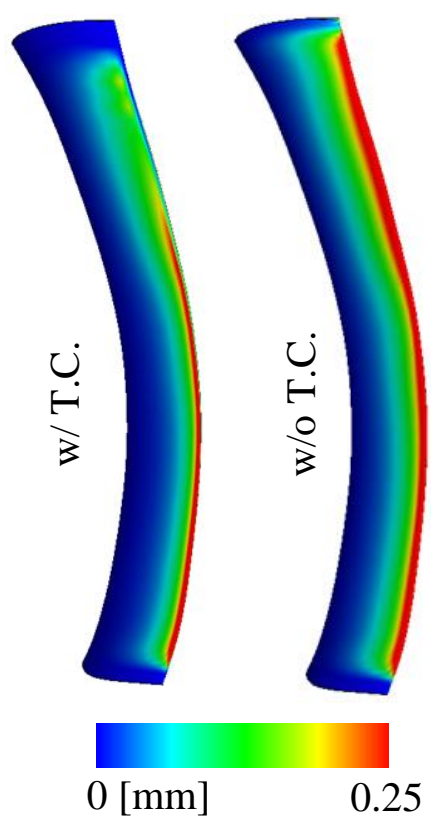

(a) Ice thickness

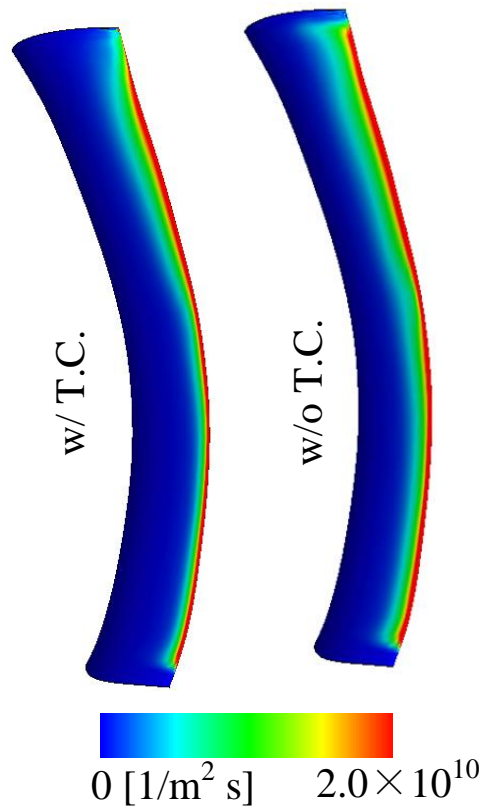

(b) Collection efficiency

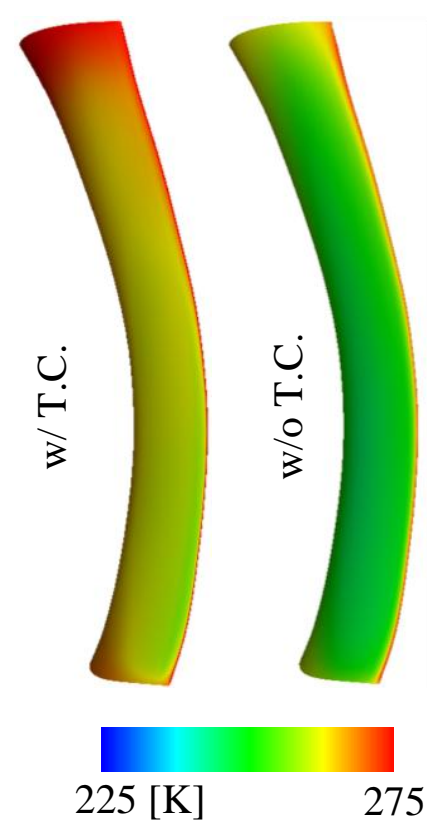

(c) Surface temperature

Figure 10 Effect of tip clearance (MVD $20 \mu \mathrm{m}$ ) 
effect of the ice accretion so that its temperature is near the freezing point and the ice accretion depends strongly on temperature.

The change of ice area at the whole cross span section in the case of $20 \mu \mathrm{m}$ droplet diameter is shown in Figure 11; (a) is on the rotor blade and (b) is on the stator vane. The ice area on the rotor blade is little affected by the tip clearance. However, the tip clearance has a huge effect on the ice area on the stator vane. As mentioned before in this section, reduction of the ice thickness, decrease of the collection efficiency and increase of the surface temperature lead to the change of the ice area on the stator vane. In particular, the total reduction of the ice area is $3.9 \%$ at the rotor blade and $18.4 \%$ at the stator vane. The ice area in the case of $50 \mu \mathrm{m}$ droplet diameter is shown in Figure 12. Paying attention to Figure 12 (a), the tip clearance has an effect on the ice area at the rotor tip side in the case of $50 \mu \mathrm{m}$ diameter. This is due to the droplets impinge on the tip unlike the case of $20 \mu \mathrm{m}$ droplet diameter as previously mentioned. The ice area at the stator vane is also different from the case with the tip

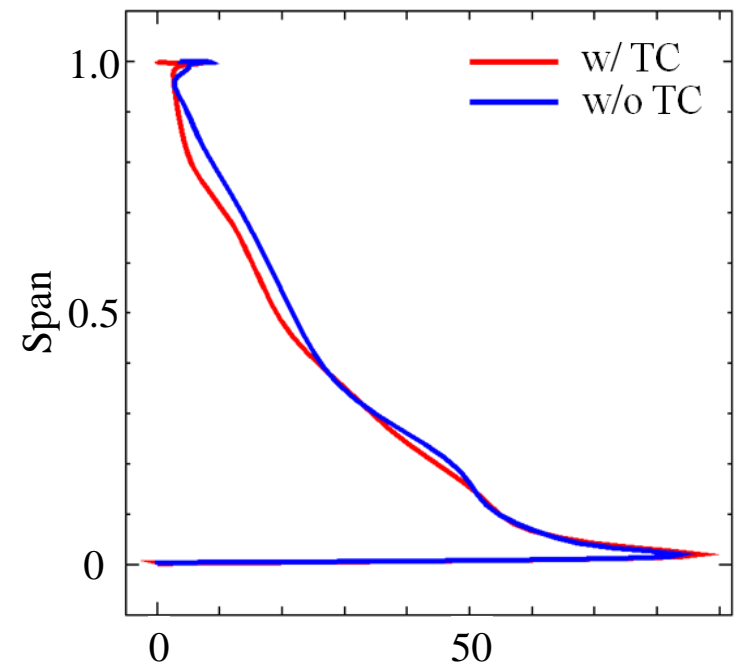

Ice area $\left[\mathrm{mm}^{2}\right]$

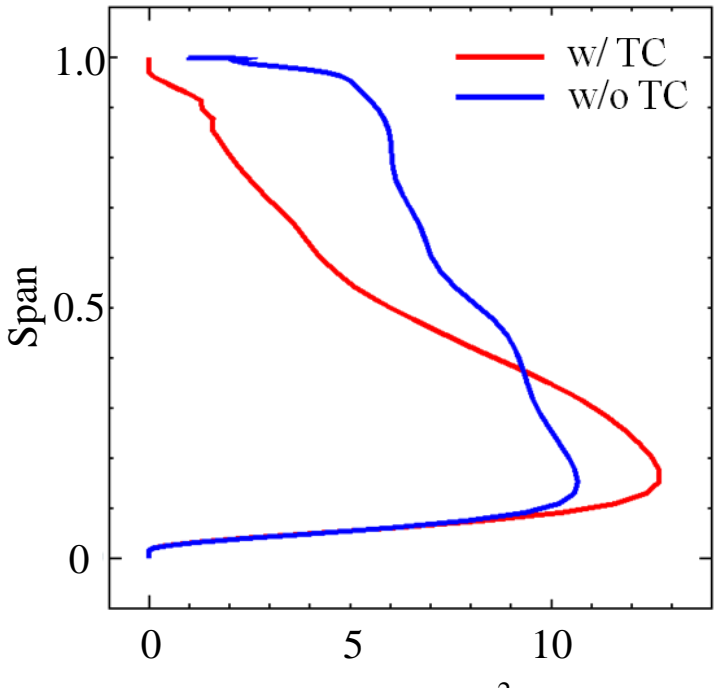

Ice area $\left[\mathrm{mm}^{2}\right]$

Figure 11 Ice area at whole span section (MVD $20 \mu \mathrm{m}$ )
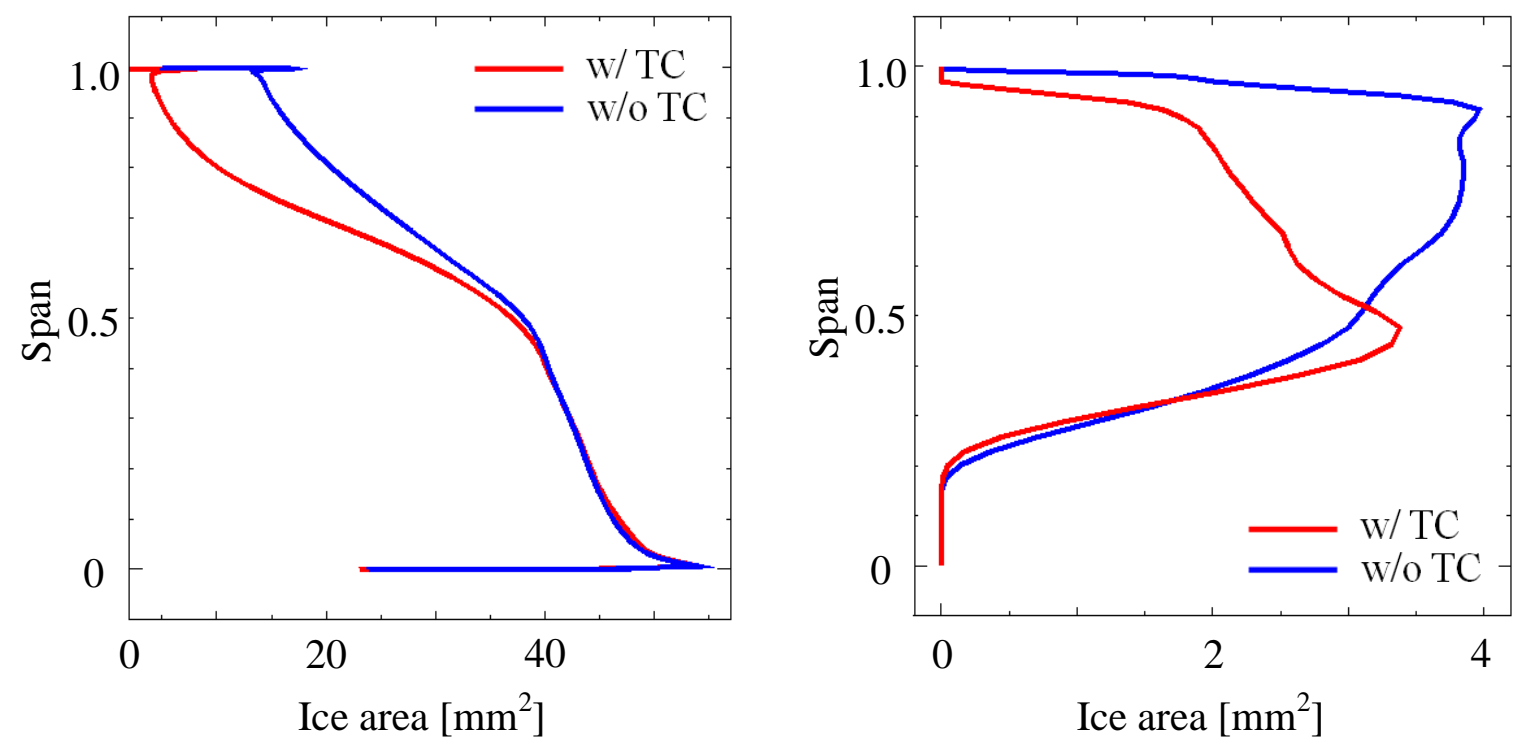

Figure 12 Ice area at whole span section (MVD $50 \mu \mathrm{m}$ ) 
clearance to the case without one as well as Figure 11 (b). The total reduction of the ice area is $6.5 \%$ at the rotor blade and $28.9 \%$ at the stator vane. Therefore, the tip clearance must be considered in simulating icing phenomena at rotor/stator interaction field because of the strong effect.

\section{CONCLUSION}

We simulate icing phenomena in the rotor/stator interaction fields with and without the tip clearance in order to clarify the effect of the tip clearance. The knowledge obtained in this study is described below:

(1) The leakage vortex leads to increase of the blade surface temperature, decrease of the collection efficiency and decrease of the ice thickness on the stator vane.

(2) In the case of $20 \mu \mathrm{m}$ droplet diameter, the reduction of the ice area is $3.9 \%$ at the rotor blade and is $18.4 \%$ at the stator vane by the effect of the tip clearance.

(3) In the case of $50 \mu \mathrm{m}$ droplet diameter, the reduction of the ice area is $6.5 \%$ at the rotor blade and is $28.9 \%$ at the stator vane by the effect of the tip clearance.

(4) The tip clearance must be considered in the design of fan blade and FEGV because of the large effect on icing phenomena.

\section{REFERENCES}

[1] Hayashi R., Kawakami K., Suzuki M,, Yamamoto M., Shishido S., Murooka T., Miyagaw H., "Numerical simulation of icing phenomena in fan rotor/stator interaction field", Proceedings of the 11th International Gas Turbine Congress, 2011.

[2] Kato M., Launder B. E., "The modeling of turbulent flow around stationary and vibrating square cylinder", Proceedings of the 8th Symposium on Turbulent Shear Flows, 10-4-110-4-6, 1993.

[3] Yee H. C., "Upwind and symmetric Shock-Capturing Schemes”, NASA-TM-89464, 1987.

[4] Fujii K., Obayashi S., "Practical application of improved LU-ADI scheme for the threedimensional Navier-Stokes computations of transonic viscous flows", AIAA Paper, 860513, 1986, also AIAA J., 25, 369-370, 1987.

[5] Ozgen S., Canibek M., "Ice accretion simulation on multi-element airfoils using extended Messinger model”, Heat and Mass Transfer, 45, 305-322, 2009.

[6] Shirayama S., Ohta T., "A visualization of a vector-field by a homogenized nascentparticles tracking ", Int. J. of Visualization, 4.2, 185-196, 2001. 